\title{
Critical Illness Neuromyopathy and the Role of Physical Therapy and Rehabilitation in Critically Ill Patients
}

\author{
Eddy Fan MD
}

\author{
Introduction \\ Etiology and Pathophysiology of ICU-Acquired Weakness \\ Immobility and Disuse Atrophy \\ Critical Illness Polyneuropathy and Myopathy \\ Risk Factors for ICU-Acquired Weakness \\ Clinical Manifestations and Diagnosis of ICU-Acquired Weakness \\ Physical Examination \\ Electrophysiological Testing \\ Muscle Biopsy \\ Epidemiology of ICU-Acquired Weakness \\ Strategies for the Prevention and Treatment of ICU-Acquired Weakness \\ Outcomes in Patients with ICU-Acquired Weakness \\ Summary and Future Directions
}

\begin{abstract}
Neuromuscular complications of critical illness are common, and can be severe and persistent, with substantial impairment in physical function and long-term quality of life. While the etiology of ICU-acquired weakness (ICUAW) is multifactorial, both direct (ie, critical illness neuromyopathy) and indirect (ie, immobility/disuse atrophy) complications of critical illness contribute to it. ICUAW is often difficult to diagnose clinically during the acute phase of critical illness, due to the frequent use of deep sedation, encephalopathy, and delirium, which impair physical examination for patient strength. Despite its limitations, physical examination is the starting point for identification of ICUAW in the cooperative patient. Given the relative cost, invasiveness, and need for expertise, electrophysiological testing and/or muscle biopsy may be reserved for weak patients with slower than expected improvement on serial clinical examination. Currently there are limited interventions to prevent or treat ICUAW, with tight glycemic control having the greatest supporting evidence. There is a paucity of clinical trials evaluating the specific role of early rehabilitation in the chronic critically ill. However, a number of studies support the benefit of intensive rehabilitation in patients receiving chronic mechanical ventilation. Furthermore, emerging data demonstrate the safety, feasibility, and potential benefit of early mobility in critically ill patients, with the need for multicenter randomized trials to evaluate potential short- and long-term benefits of early mobility, including the potential to prevent the need for prolonged mechanical ventilation and/or the development of chronic critical illness, and other novel treatments on patients' muscle strength, physical function, quality of life, and resource utilization. Finally, the barriers, feasibility, and efficacy of early mobility in both medical and other ICUs (eg, surgical, neurological, pediatric), as well as in the chronic critically ill, have not been formally evaluated and require exploration in future clinical trials. Key words: bed rest; critical care; early ambulation; intensive care units; muscle weakness; neuromuscular diseases; paresis. [Respir Care 2012;57(6):933-944. (C) 2012 Daedalus Enterprises]
\end{abstract}




\section{Critical Illness Neuromyopathy and the Role of Physical Therapy and Rehabilitation}

\section{Introduction}

Over recent decades, decreasing mortality from critical illness has led to an increasing number of ICU survivors. ${ }^{1,2}$ Understanding the post-ICU morbidity experienced by these survivors has become increasingly important. In particular, neuromuscular abnormalities during critical illness are common, with a median prevalence of $57 \%$ (range $9-87 \%) .{ }^{3}$ In both patients with chronic critical illness and survivors of severe critical illness, neuromuscular weakness may be substantial and persistent, resulting in important decrements in physical function and quality of life. ${ }^{4-7}$

The etiology of neuromuscular weakness in critically ill patients is multifactorial. ${ }^{8}$ Some ICU patients have premorbid weakness associated with other chronic disease. However, there is growing recognition that both critical illness and its associated treatments lead to muscle and nerve injury. Disuse atrophy from prolonged immobility and specific conditions, such as critical illness polyneuropathy (CIP) and critical illness myopathy (CIM), contribute to ICU-acquired weakness (ICUAW). No specific treatment exists for ICUAW. Understanding its etiology, pathophysiology, and risk factors may be important for prevention. This review addresses these issues and provides an approach to the diagnosis and management of ICUAW.

\section{Etiology and Pathophysiology of ICU-Acquired Weakness}

\section{Immobility and Disuse Atrophy}

Prolonged immobility from bed rest is common in many ICUs and may contribute to ICUAW. ${ }^{9,10}$ Immobility leads to decreased muscle protein synthesis, increased muscle catabolism, and decreased muscle mass, especially in the lower extremities..$^{11,12}$ These changes manifest as reduced cross-sectional muscle area and decreased contractile strength. Moreover, there is a general shift from slow twitch (type I) to fast twitch (type II) muscle fibers, lead-

Dr Fan is affiliated with the Interdepartmental Division of Critical Care Medicine, University of Toronto, Toronto, Ontario, Canada.

Dr Fan presented a version of this paper at the 49th Respiratory CARE Journal Conference, "The Chronically Critically Ill Patient," held September 9-10, 2011, in St Petersburg, Florida.

Dr Fan was supported by a Fellowship Award from the Canadian Institutes of Health Research. Dr Fan has disclosed no conflicts of interest.

Correspondence: Eddy Fan MD, Mount Sinai Hospital, 600 University Avenue, Room 18-232, Toronto, Ontario M5G 1X5 Canada. E-mail: efan@mtsinai.on.ca.

DOI: $10.4187 /$ respcare. 01634 ing to reduced muscle endurance. ${ }^{13}$ Experiments in healthy volunteers reveal that muscle atrophy begins within hours of immobility, ${ }^{14}$ resulting in a $4-5 \%$ loss of muscle strength for each week of bed rest. ${ }^{15}$ The interaction of critical illness with immobility may lead to even greater muscle loss. ${ }^{16}$ In a prospective study of 109 ARDS survivors, patients lost $18 \%$ of their baseline body weight by ICU discharge. ${ }^{6}$ Age may also be an important factor, as more elderly sarcopenic patients are admitted to the ICU, and begin with a lower muscle mass at baseline. ${ }^{17}$ Furthermore, muscle quality declines with aging, resulting in increased intramuscular fat, with associated decreased muscle thickness and cross-sectional area. ${ }^{18}$ Short-term immobility also impairs microvascular function and induces insulin resistance, ${ }^{19}$ which may contribute to neuromuscular injury in the critically ill. Finally, immobility increases production of pro-inflammatory cytokines and reactive oxygen species, resulting in further muscle proteolysis, with a net loss of muscle protein and subsequent muscle weakness. ${ }^{20}$

\section{Critical Illness Polyneuropathy and Myopathy}

First described in 1984 in association with sepsis, CIP is a diffuse and symmetric sensorimotor axonal neuropathy. ${ }^{21}$ The mechanism of axonal degeneration may be multifactorial, including: impaired oxygen and nutrient delivery from microcirculatory dysfunction in peripheral nerves, due to sepsis and/or hyperglycemia, and increased endoneuronal edema, due to cytokine-induced changes in microvascular permeability; and neuronal bioenergetic failure from mitochondrial dysfunction, due to increased uptake of glucose and subsequent reactive oxygen species generation. ${ }^{22,23}$ Furthermore, cytokines may exert direct toxic effects on peripheral nerves, and there may be a humoral neurotoxic factor involved in the pathogenesis of CIP. ${ }^{24}$

CIM represents a spectrum of ICU-acquired muscle pathology involving metabolic, inflammatory, and bioenergetic muscle derangements. Decreased oxygen and nutrient delivery to muscles, upregulation of protein catabolism by pro-inflammatory cytokines, decreased expression of myofibrillar repair genes, and an imbalance in anabolic and catabolic hormones contribute to CIM. ${ }^{22,23}$ Functional inactivation of the remaining muscle may occur due to membrane inexcitability from acquired ionchannel dysfunction and excitation-contraction decoupling, due to impaired calcium release within muscle fibers. ${ }^{25}$

CIP and CIM often coexist, commonly referred to collectively as critical illness neuromyopathy (CINM). Muscle that is functionally denervated (from CIP) and directly injured (from CIM) may have increased susceptibility to additional insults and injury (eg, corticosteroid-induced myopathy). ${ }^{26}$ Furthermore, weakness from CINM may be enhanced by immobility. ${ }^{27}$ 
In addition to the effects of critical illness on skeletal muscle, diaphragmatic involvement may occur, with atrophy and reduced muscle force..$^{28}$ In a study of brain-dead organ donors (with effective functional denervation), even short-term diaphragmatic inactivity with controlled mechanical ventilation may result in marked diaphragmatic atrophy. ${ }^{29}$ We hypothesize that this "2-hit" combination of immobilization and the early development of subclinical CINM may contribute to rapid muscle atrophy. ${ }^{30}$

\section{Risk Factors for ICU-Acquired Weakness}

Although there are a number of commonly cited risk factors for ICUAW (Table 1), many lack consistent support from methodologically rigorous clinical studies. ${ }^{3,40}$ Furthermore, heterogeneous patient populations and the lack of an accepted taxonomy for ICUAW make comparisons across studies difficult. ${ }^{3,41}$

There are limited and conflicting data regarding the association between patient demographics and severity of illness with ICUAW. ${ }^{3,40}$ Hyperglycemia is the most consistently identified risk factor for ICUAW. ${ }^{3,40}$ Subgroup analyses from 2 large, single-center, randomized trials ${ }^{31,39}$ demonstrated a substantial decrease in ICUAW (relative risk $0.65,95 \%$ CI $0.55-0.78$ ) in patients receiving intensive insulin therapy for tight glycemic control who were mechanically ventilated for $\geq 7$ days. ${ }^{40}$ However, since ICUAW was not the primary outcome in either trial, conclusions from these subgroup analyses have important limitations. ${ }^{40}$

There is substantial controversy regarding the role of systemic corticosteroids in ICUAW. A prospective study reported that corticosteroids was the single largest risk factor for ICUAW (odds ratio [OR] 14.9, 95\% CI 3.269.8). ${ }^{4}$ However, a number of other studies, including systematic reviews, failed to demonstrate a consistent association between corticosteroids and ICUAW.3,31-39 Conversely, a recent study demonstrated decreased ICUAW in patients randomized to intensive insulin therapy who also received corticosteroids in the ICU (OR $0.91,95 \%$ CI 0.86-0.97). ${ }^{31}$ Hyperglycemia may partially mediate the deleterious effects of corticosteroids on the neuromuscular system, such that the anti-inflammatory effects of corticosteroids may be protective against ICUAW when blood glucose is strictly controlled. ${ }^{31,34}$

Despite early reports of persistent weakness following prolonged administration of neuromuscular blockade, 6 prospective studies did not find a significant association with ICUAW.4,34-37,39 A significant association reported in 2 other studies may have resulted from larger doses and a longer duration of neuromuscular blockade than occurs in current clinical practice. ${ }^{31,38}$

\section{Clinical Manifestations and Diagnosis of ICU-Acquired Weakness}

ICUAW is often difficult to diagnose clinically during the acute phase of critical illness, due to the frequent use of deep sedation, encephalopathy, and delirium, which impair physical examination for patient strength. ${ }^{42}$ Consequently, ICUAW is typically recognized during recovery from critical illness when there is either prolonged or failed weaning from mechanical ventilation or profound weakness or quadriplegia in an awake patient. ${ }^{43}$

\section{Physical Examination}

Physical examination of muscle strength is commonly conducted using the Medical Research Council (MRC) scale (range: $0=$ no muscle contraction, to $5=$ normal strength). ${ }^{44}$ Such physical examination can be challenging because it requires patient effort and cooperation, which may be limited by sedation, delirium, or coma. ${ }^{45}$ As a measure of overall muscle strength, a composite MRC score from examination of 3 muscle groups in each limb is commonly used. This composite MRC score has excellent inter-rater reliability within specific non-ICU patient populations, as well as in survivors of critical illness. ${ }^{45-47}$ Clinically important muscle weakness has been arbitrarily defined as a composite MRC score $<80 \%$ of normal (eg, a score $<48$ out of a maximum of 60 based on examination of 3 muscle groups in each limb).4,46,48 Typically, symmetric weakness is observed in all limbs, ranging from mild paresis to frank quadriplegia. In non-cooperative patients with ICUAW, noxious stimuli applied to each extremity may elicit facial grimacing with limited or absent patient withdrawal, reflecting the typical pattern of peripheral weakness with relative sparing of facial muscles.

Similar to the motor examination, the sensory examination is frequently limited by sedation, delirium, and/or peripheral edema. Deep tendon reflexes may be diminished or absent in CINM, but normal reflexes do not rule out ICUAW. Hyper-reflexia or associated spasticity suggests an alternative diagnosis (eg, central nervous system etiology), and further investigations (eg, brain and spinal cord imaging) should be considered.

\section{Electrophysiological Testing}

Given the limitations of physical examination, electrophysiological testing (ie, motor/sensory nerve conduction studies and needle electromyography) may be used in the diagnostic workup for ICUAW. In patients with CIP, nerve conduction studies often reveal a mixed sensorimotor axonopathy (ie, reduced compound muscle action potential and sensory nerve action potential amplitudes) with relative preservation of the nerve conduction veloc- 


\section{Critical Illness Neuromyopathy and the Role of Physical Therapy and Rehabilitation}

Table 1. Risk Factors for ICU-Acquired Weakness

\begin{tabular}{|c|c|c|c|c|}
\hline Risk Factor & Study Design* & $N$ & Definition of ICUAW & Evidence of Association \\
\hline \multicolumn{5}{|l|}{ Patient Factors } \\
\hline \multirow[t]{4}{*}{ Age } & Prospective & 95 & Clinical & No association between age and ICUAW ${ }^{4}$ \\
\hline & Secondary analysis* & 420 & Electrophysiological testing & $\begin{array}{l}\text { Older age negatively associated (OR } 0.98 \\
95 \% \text { CI } 0.96-0.99 \text { per year) with ICUAW }{ }^{31}\end{array}$ \\
\hline & Retrospective & 50 & Clinical & $\begin{array}{l}\text { Older age significantly associated with ICUAW } \\
\qquad(P=.01)^{32}\end{array}$ \\
\hline & Secondary analysis & 128 & Clinical & No association between age and ICUAW ${ }^{33}$ \\
\hline \multirow[t]{4}{*}{ Sex } & Prospective & 95 & Clinical & $\begin{array}{l}\text { Female sex significantly associated (OR 4.7, } \\
95 \% \text { CI 1.2-18.3) with ICUAW }{ }^{4}\end{array}$ \\
\hline & Secondary analysis & 420 & Electrophysiological testing & No association between sex and ICUAW ${ }^{31}$ \\
\hline & Prospective & 474 & Clinical & No association between sex and ICUAW ${ }^{34}$ \\
\hline & Secondary analysis & 128 & Clinical & No association between sex and ICUAW ${ }^{33}$ \\
\hline \multirow[t]{8}{*}{ Severity of illness } & Prospective & 95 & Clinical & $\begin{array}{l}\text { No association between admission SAPS II } \\
\text { score and ICUAW }\end{array}$ \\
\hline & Secondary analysis & 420 & Electrophysiological testing & $\begin{array}{l}\text { No association between admission APACHE II } \\
\text { score or maximal daily SOFA score and } \\
\text { ICUAW }^{31}\end{array}$ \\
\hline & Prospective & 61 & Clinical, electrophysiological testing & $\begin{array}{l}\text { Admission SOFA score significantly associated } \\
\text { (OR } 1.15,95 \% \text { CI 1.02-1.36) with } \\
\text { ICUAW }^{35}\end{array}$ \\
\hline & Prospective & 98 & Clinical, electrophysiological testing & $\begin{array}{l}\text { Admission APACHE III score significantly } \\
\text { associated }(P<.05) \text { with ICUAW in } \\
\text { multivariable analysis }\end{array}$ \\
\hline & Prospective & 474 & Clinical & $\begin{array}{l}\text { Admission APACHE II score significantly } \\
\text { associated (OR 1.08, 95\% CI 1.02-1.15) } \\
\text { with ICUAW }\end{array}$ \\
\hline & Prospective & 44 & $\begin{array}{l}\text { Clinical, electrophysiological testing, } \\
\text { muscle biopsy }\end{array}$ & $\begin{array}{l}\text { No association between APACHE II score and } \\
\text { ICUAW }{ }^{37}\end{array}$ \\
\hline & Retrospective & 50 & Clinical & $\begin{array}{l}\text { No association between SAPS-2 or SOFA } \\
\text { score and ICUAW }{ }^{32}\end{array}$ \\
\hline & Prospective & 73 & Electrophysiological testing & $\begin{array}{l}\text { No association between APACHE II score and } \\
\text { ICUAW }^{38}\end{array}$ \\
\hline \multicolumn{5}{|l|}{ ICU Exposures } \\
\hline \multirow[t]{5}{*}{ Blood glucose } & Prospective & 95 & Clinical & $\begin{array}{l}\text { No association between daily blood glucose } \\
\text { level and ICUAW }\end{array}$ \\
\hline & Secondary analysis & 405 & Electrophysiological testing & $\begin{array}{l}\text { Hyperglycemia significantly associated } \\
\text { (OR } 1.26,95 \% \text { CI } 1.09-1.46 \text { per mmol } \\
\text { blood glucose) with ICUAW }{ }^{39}\end{array}$ \\
\hline & Secondary analysis & 420 & Electrophysiological testing & $\begin{array}{l}\text { Tight glycemic control significantly reduced } \\
\text { the incidence of ICUAW (51\% vs } 39 \% \\
P=.02)^{31}\end{array}$ \\
\hline & Prospective & 474 & Clinical & $\begin{array}{l}\text { Hyperglycemia significantly associated } \\
\text { (OR 2.86, 95\% CI 1.30-6.30) with } \\
\text { ICUAW }^{37}\end{array}$ \\
\hline & Retrospective & 50 & Clinical & $\begin{array}{l}\text { Highest daily glucose level significantly } \\
\text { associated }(P<.001) \text { with ICUAW }{ }^{32}\end{array}$ \\
\hline \multirow[t]{5}{*}{ Corticosteroids } & Prospective & 95 & Clinical & $\begin{array}{l}\text { Corticosteroids significantly associated } \\
\quad(\text { OR } 14.9,95 \% \text { CI } 3.2-69.8) \text { with ICUAW }\end{array}$ \\
\hline & Secondary analysis & 405 & Electrophysiological testing & $\begin{array}{l}\text { No association between corticosteroids and } \\
\text { ICUAW }^{39}\end{array}$ \\
\hline & Secondary analysis & 420 & Electrophysiological testing & $\begin{array}{l}\text { Corticosteroids negatively associated (OR } 0.91 \\
95 \% \text { CI } 0.86-0.97 \text { ) with ICUAW in patients } \\
\text { receiving tight glycemic control }{ }^{31}\end{array}$ \\
\hline & Prospective & 61 & Clinical, electrophysiological testing & $\begin{array}{l}\text { No association between corticosteroids and } \\
\text { ICUAW }{ }^{35}\end{array}$ \\
\hline & Prospective & 98 & Clinical, electrophysiological testing & $\begin{array}{l}\text { No association between corticosteroids and } \\
\text { ICUAW }^{36}\end{array}$ \\
\hline
\end{tabular}




\section{Critical Illness Neuromyopathy and the Role of Physical Therapy and Rehabilitation}

Table 1. Risk Factors for ICU-Acquired Weakness (continued)

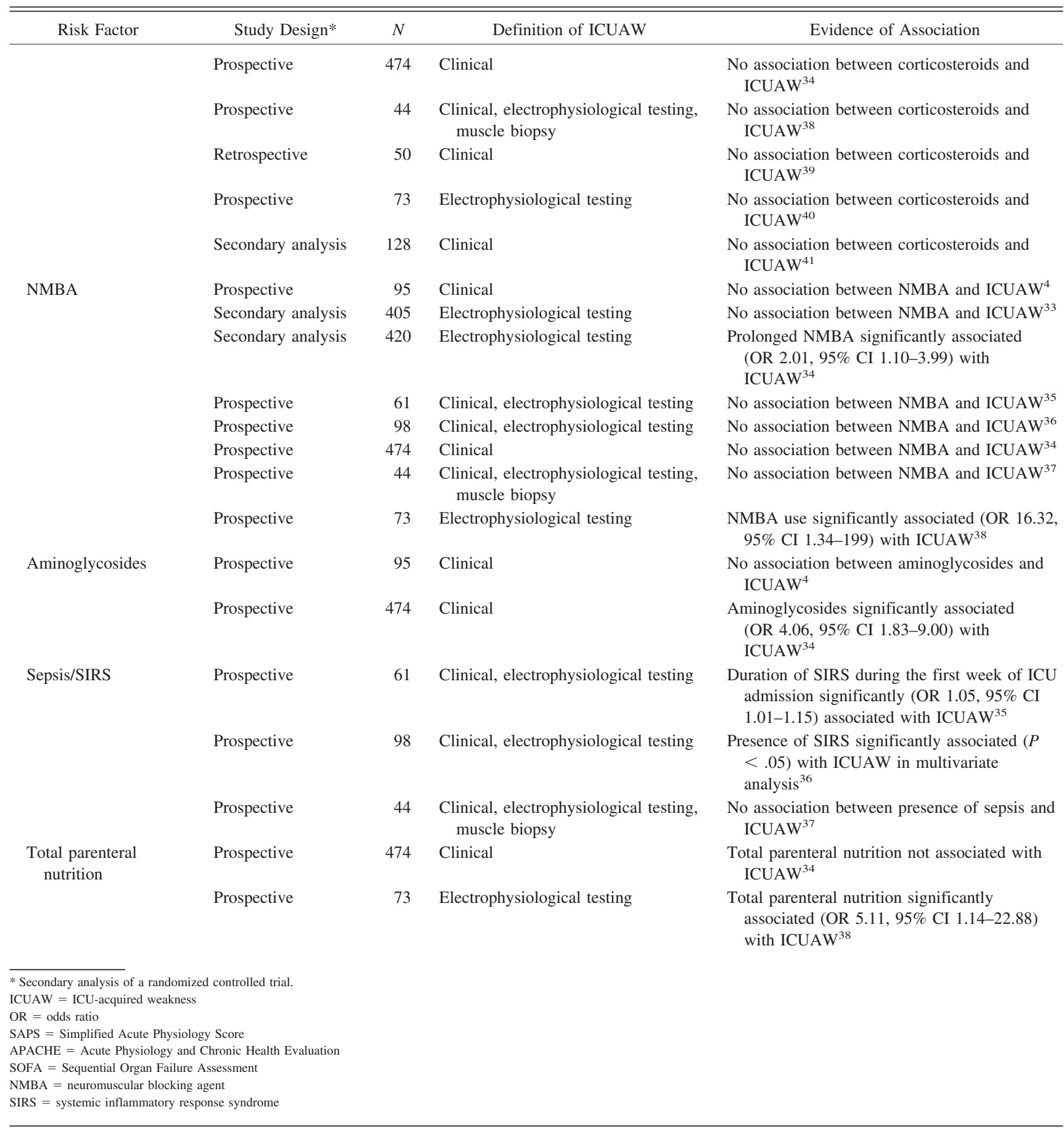

ity. ${ }^{22}$ These electrophysiologic changes can be detected as early as 24-48 hours following the onset of critical illness, and often precede clinical findings in these patients. ${ }^{49}$ Despite their potential utility in sedated or comatose patients, certain technical factors, including local edema and limb temperature, can interfere with nerve conduction studies testing. ${ }^{50}$
In patients with CIM, prolongation of compound muscle action potential duration suggests the presence of a myopathic process (ie, not due to muscle denervation). ${ }^{50}$ Direct muscle stimulation may yield reduced or absent responses in CIM, but normal responses in CIP. On needle electromyography, CIM will manifest as short duration, low amplitude motor unit action potentials, with early recruitment 
Table 3. Diagnostic Approach to ICU-Acquired Weakness

\begin{tabular}{|c|c|c|c|c|}
\hline & $\begin{array}{l}\text { Onset of Critical Illness/ } \\
\text { ICU Admission }\end{array}$ & $\rightarrow$ Patient Awakening & $\rightarrow \quad \begin{array}{c}\text { Resolution of Non- } \\
\text { Neuromuscular Organ Failure }\end{array}$ & ICU Discharge \\
\hline Diagnostic question & $\begin{array}{l}\text { Are there pre-morbid or } \\
\text { other causes of } \\
\text { weakness present? }\end{array}$ & $\begin{array}{l}\text { Is the patient sedated and/ } \\
\text { or delirious? }\end{array}$ & $\begin{array}{l}\text { Is there peripheral muscle weakness } \\
\text { and/or failure to wean from } \\
\text { mechanical ventilation? }\end{array}$ & $\begin{array}{l}\text { Is there severe and } \\
\text { persistent muscle } \\
\text { weakness and/or } \\
\text { failure to wean } \\
\text { from mechanical } \\
\text { ventilation? }\end{array}$ \\
\hline Diagnostic considerations & $\begin{array}{l}\text { Consider pre-morbid } \\
\text { weakness due to } \\
\text { chronic diseases (eg, } \\
\text { COPD) and/or non- } \\
\text { ICU acquired causes } \\
\text { of weakness (eg, } \\
\text { stroke, demyelinating } \\
\text { diseases) }\end{array}$ & $\begin{array}{l}\text { Minimize heavy sedation } \\
\text { using goal-directed } \\
\text { sedation and/or daily } \\
\text { interruption to allow } \\
\text { for serial neurological } \\
\text { examination }\end{array}$ & $\begin{array}{l}\text { Diffuse, symmetrical muscle } \\
\text { weakness with preserved/depressed } \\
\text { deep tendon reflexes is consistent } \\
\text { with ICU-acquired weakness }\end{array}$ & $\begin{array}{l}\text { Patients with severe } \\
\text { and non-resolving } \\
\text { weakness may warrant } \\
\text { further testing and/or } \\
\text { specialist consultation }\end{array}$ \\
\hline Investigations & $\begin{array}{l}\text { Obtain history of pre- } \\
\text { morbid physical } \\
\text { function and rule out } \\
\text { non-ICU acquired } \\
\text { causes of weakness }\end{array}$ & $\begin{array}{l}\text { Serial evaluations of } \\
\text { sedation and delirium } \\
\text { status }\end{array}$ & Serial neurological examination & $\begin{array}{l}\text { Consider consultation } \\
\text { with a neurologist and/ } \\
\text { or physiatrist, } \\
\text { and electromyography/ } \\
\text { nerve conduction study, } \\
\text { muscle enzymes (eg, } \\
\text { creatine kinase), and/or } \\
\text { muscle biopsy }\end{array}$ \\
\hline
\end{tabular}

(From Reference 8, with permission.)

the reported incidence among patients ventilated for at least 7 days rises to approximately $45-58 \% .^{34,54}$ ICUAW may develop in the majority of patients with sepsis. ${ }^{49,55,56}$ Taken together, neuromuscular abnormalities during critical illness are common, with a median prevalence, among studies included in a recent systematic review, of $57 \%$ (range 9-87\%) in ICU patients with sepsis, multi-organ failure, or PMV. ${ }^{3}$

\section{Strategies for the Prevention and Treatment of ICU-Acquired Weakness}

Currently, there are few rigorously evaluated interventions for the prevention and/or treatment of ICUAW. ${ }^{3,40}$ Minimizing patient exposure to corticosteroids and/or neuromuscular blocking agents, when possible, may be prudent until future studies can clarify the role of these agents in ICUAW. At present, the strongest evidence for prevention of ICUAW is tight glycemic control with intensive insulin therapy. ${ }^{31,39}$ However, the potential benefits of intensive insulin therapy should be carefully weighed against the possibility of serious hypoglycemia, and there continues to be uncertainty regarding the optimal blood glucose range in critically ill patients. ${ }^{57}$ Results from the recent multicenter Normoglycemia in Intensive Care Evaluation and Survival Using Glucose Algorithm Regulation (NICESUGAR) trial demonstrated no significant difference in days of mechanical ventilation $(P=.56)$, ICU $(P=.84)$ or hospital stay $(P=.86)$ between groups, suggesting potentially no clinically important effect of intensive insulin therapy in the prevention or attenuation of ICUAW. ${ }^{58}$ Finally, despite the lack of high quality evidence, maintenance of electrolyte homeostasis (eg, phosphate, magnesium) and adequate nutrition may be reasonable recommendations for minimizing weakness. ${ }^{43}$

A relatively new therapeutic option being evaluated for prevention and treatment of ICUAW is early rehabilitation and mobilization of patients in the ICU. ${ }^{9}$ Having critically ill patients alert and engaged in progressive rehabilitation (eg, passive range of motion, active range of motion/bed exercises, sitting at edge of bed, transfers) leading to mobilization, despite the use of life support therapies, may reduce muscle atrophy and lead to improved strength and physical function. Moreover, mobilization and exercise may decrease oxidative stress and inflammation, $, 9,20$ and prevent insulin resistance and microvascular dysfunction, ${ }^{19}$ which may ameliorate ICUAW.

There is a paucity of clinical trials evaluating the specific role of early rehabilitation in the chronic critically ill. However, a number of studies have examined the role of rehabilitation in patients receiving chronic mechanical ventilation. In a case series of 16 ventilator-dependent patients referred to an in-patient pulmonary rehabilitation unit, a progressive 5 phase multidisciplinary (physical, 


\section{Critical Illness Neuromyopathy and the Role of Physical Therapy and Rehabilitation}

occupational, and respiratory therapy) rehabilitation program resulted in most patients (63\%) being independent with most or all of their activities of daily living at discharge. ${ }^{59}$ A retrospective study of 49 severely weak and bedridden, chronically ventilator-dependent patients (mean 18 d) referred to a tertiary care ventilator rehabilitation unit examined the effect of their progressive whole body rehabilitation program $(5 \mathrm{~d}$ per week in an on-site gym) on patient functional outcomes. ${ }^{60}$ At ventilator rehabilitation unit discharge, the patients had significantly improved upper and lower limb motor strength, as well as functional independence (as measured by the functional independence measurement score). All 49 patients were weaned from mechanical ventilation, although 3 patients subsequently required intermittent ventilatory support, could sit and stand, and the majority (40 patients) could ambulate at ventilator rehabilitation unit discharge. Importantly, there were no adverse events related to the rehabilitation program.

At present, there is a single report of a randomized controlled trial evaluating an early rehabilitation program in chronically ill patients admitted to a respiratory ICU (RICU). ${ }^{61}$ Patients with COPD following an episode of acute respiratory failure (with approximately $50 \%$ requiring invasive mechanical ventilation) were randomized to intensive pulmonary rehabilitation (60 patients) versus standard therapy (20 patients) after admission to a RICU. The pulmonary rehabilitation group initiated therapy within 24 hours of RICU admission, which consisted of twice daily, 30-45 min sessions focused on lower extremity and respiratory muscle training (using threshold device and breathing twice daily at target pressure of $50 \%$ of maximal inspiratory pressure), with a goal of progressing to ambulation. The standard therapy group had no specific lower extremity or respiratory muscle training early in their RICU admission. While there was no significant difference between groups in proportion regaining the ability to ambulate ( $87 \%$ vs $70 \%, P=.09$ ), the pulmonary rehabilitation group had significantly greater improvements in 6-min walk distance $(100 \mathrm{~m})$, maximal inspiratory pressure $16 \mathrm{~cm} \mathrm{H}_{2} \mathrm{O}$ ), and dyspnea scores (45\%) from their baseline status, as compared to the standard therapy group.

More recently, studies have demonstrated that early mobilization, including ambulation, of mechanically ventilated patients is safe and feasible, even when occurring immediately after physiological stabilization, within 2472 hours of acute ICU admission. ${ }^{62-66}$ Uncontrolled studies of early mobility have been associated with greater activity levels and functional outcomes, versus usual care, in which mobility is frequently delayed until after ICU discharge. ${ }^{64}$ A single-center, non-randomized controlled trial in 330 mechanically ventilated patients built on this earlier research demonstrating that a dedicated multidisciplinary mobility team (critical care nurse, nursing assis- tant, physical therapist), using a physical rehabilitation protocol, was associated with increased physical therapy and a shorter time for patients to be first out of bed $(5.0 \mathrm{~d}$ vs $11.3 \mathrm{~d}, P<.001$ adjusted for body mass index, severity of illness, and vasopressor use). ${ }^{62}$ Moreover, patients treated with the early mobility protocol experienced a decrease in ICU stay (5.5 d vs $6.9 \mathrm{~d}$, adjusted $P=.025$ ) and hospital stay (11.2 d vs $14.5 \mathrm{~d}$, adjusted $P=.006)$ among survivors. In addition, there was a trend toward a decreased duration of mechanical ventilation ( $8.8 \mathrm{~d}$ vs $10.2 \mathrm{~d}$, adjusted $P=.16)$ and reduced hospital mortality (12\% vs $18 \%, P=.13$ ), without a significant increase in hospital costs, despite the added expense of the mobility team (mean cost per patient $\$ 41,142$ vs $\$ 44,302, P=.26$ ). Temporal trends indicating improved ICU and hospital stay, and declining rates of tracheostomy (29\% vs 5\%) and failure to wean from mechanical ventilation (12\% vs $3 \%)$, also have been reported at another center. ${ }^{66}$

Combining protocols for early mobility and sedation management may have synergistic benefits, as demonstrated in a prior trial that combined protocols for sedation and ventilator weaning. ${ }^{67}$ To that end, a recent randomized controlled trial evaluating the use of early rehabilitation in the ICU randomized 104 mechanically ventilated patients to either early exercise and mobilization combined with daily interruption of sedation or daily interruption of sedation alone. ${ }^{68}$ Patients in the therapy group had physical and occupational therapy initiated early, as compared to controls (median $1.5 \mathrm{~d}$ vs $7.4 \mathrm{~d}$ after intubation, $P<.001$ ). Patients in the intervention group had shorter duration of delirium (median $2 \mathrm{~d}$ vs $4 \mathrm{~d}, P=.02$ ) and more ventilatorfree days ( $23.5 \mathrm{~d}$ vs $21.1 \mathrm{~d}, P=.05)$. Serious adverse events were rare. A greater proportion of patients had a return to independent functional status at hospital discharge in the intervention group (59 vs $35 \%, P=.02$ ). These encouraging results require further investigation in multicenter randomized trials.

Barriers to early mobility, both real (eg, oversedation) and perceived (eg, vasopressors, obesity), represent substantial challenges to translating this intervention into practice in many ICUs. ${ }^{69-72}$ An important step in developing a successful early mobility program in the ICU requires a paradigm shift away from bed rest and heavy sedation, and toward a culture of prioritizing awake, spontaneously breathing patients and a focus on early rehabilitation. ${ }^{73}$ Creating a supportive ICU culture for early mobilization through interdisciplinary cooperation, coordination, and communication are integral to the successful and sustained implementation of this complex intervention. ${ }^{65,66,72}$ Local representation and champions from each relevant discipline (eg, critical care, physiatry, nursing, physical/occupational therapy, respiratory therapy) to create a vision and guiding coalition to prioritize early 


\section{Critical Illness Neuromyopathy and the Role of Physical Therapy and Rehabilitation}

rehabilitation and mobilization is key to transforming ICU culture. ${ }^{66}$

Coordination between members of the interdisciplinary team (bedside nurses, physical and respiratory therapists) is key in order to provide the most effective rehabilitation experience for mechanically ventilated patients. Mechanically ventilated patients may require increased $\mathrm{F}_{\mathrm{IO}_{2}}$ and/or a change in ventilator mode (eg, from pressure support to pressure control or continuous mandatory ventilation) to facilitate tolerance of the planned activity. Given the amount of equipment (eg, portable monitor, oxygen tanks, infusion pumps, wheelchair) and personnel (eg, physical and respiratory therapist, nurse) required to ambulate mechanically ventilated patients, the use of portable ventilators may facilitate mobility sessions, particularly in space-limited settings. ${ }^{65}$ Patients receiving supplemental oxygen at the onset of therapy may require the use of noninvasive ventilation to tolerate their sessions. Modifications to the patients' ventilator requirements can often be determined by careful monitoring of the patient's respiratory status during therapy, as well as from their tolerance of prior rehabilitation sessions.

Novel rehabilitation technology, such as neuromuscular electrical stimulation and cycle ergometry, may be useful adjunctive therapies within the context of an ICU early rehabilitation program. ${ }^{74}$ Neuromuscular electrical stimulation induces passive contraction of muscles through lowvoltage electrical impulses delivered through skin electrodes placed over target muscle groups (eg, quadriceps), and may be helpful in mitigating the development of muscle atrophy and weakness among high-risk critically ill patients. ${ }^{75,76}$ Bedside cycle ergometry can provide muscle strength training and range of motion exercises for ICU patients who are either awake (active cycling) or sedated (passive cycling), and may also preserve muscle strength and function. ${ }^{77}$ The role of these rehabilitation technologies in both the acute and chronic critically ill require confirmation in large, prospective clinical trials.

\section{Outcomes in Patients with ICU-Acquired Weakness}

Prolonged weaning from mechanical ventilation is a common manifestation of ICUAW. A recent systematic review revealed that ICUAW was associated with PMV and ICU and hospital stay. ${ }^{3}$ In one study of 64 septic patients (34 with CIP), the presence of ICUAW was the only significant predictor of failure to wean from mechanical ventilation (OR 15.4, 95\% CI 4.6-52.3). ${ }^{78}$

Existing evidence is inconclusive regarding whether ICUAW is independently associated with increased hospital mortality. ${ }^{3,40,79}$ A recent study demonstrated that hospital non-survivors had a significantly higher rate of ICUAW ( $85 \%$ vs $58 \%, P=.02)$ and that the presence of ICUAW at patient awakening was independently associ- ated with higher ICU (OR 7.99, 95\% CI 0.99-64.29) and hospital mortality (OR 2.02, 95\% CI 1.03-8.03). ${ }^{80}$ Furthermore, ICUAW was associated with hospital mortality in a dose-dependent manner (OR 1.03 per 1-point decrement in the MRC score, 95\% CI 1.01-1.05). However, in survivors recovery from ICUAW is possible, with a majority $(94 \%)$ of patients in one cohort demonstrating meaningful improvement of muscle strength at 9 months. ${ }^{4}$ However, at hospital discharge, many patients with ICUAW require transfer to an in-patient rehabilitation facility in order to slowly progress toward their pre-morbid level of functioning. ${ }^{50,81}$ In a study of 128 ICU patients with acute lung injury, those with ICUAW returned home significantly later than patients without ICUAW (56 d vs $35 \mathrm{~d}$, $P=.005) .^{41}$

In some patients, ICUAW may result in severe and prolonged weakness and impaired physical function and quality of life. ${ }^{4-7,48,56,82}$ Patients may demonstrate both clinical and electrophysiological signs of ICUAW up to 12 months following hospital discharge, with some experiencing severe weakness and paralysis. ${ }^{48,56}$ During 1-year follow-up in a study of 109 ARDS survivors, all patients reported poor functional status following ICU discharge, which was attributed to muscle loss, weakness, and fatigue. ${ }^{6}$ Moreover, these persistent impairments contributed to the inability to return to work in more than half of these patients. ${ }^{6}$ Finally, these limitations in physical function may contribute to the decrements in health-related quality of life reported in these patients at up to 5 years from ICU discharge. $6,7,81$

\section{Summary and Future Directions}

Neuromuscular complications of critical illness are common, and can be severe and persistent, with substantial impairment in long-term quality of life. While the etiology of ICUAW is multifactorial, both direct (ie, CIP/CIM) and indirect (ie, immobility/disuse atrophy) complications of critical illness contribute to it. Importantly, a commonly accepted set of definitions, diagnostic criteria, and taxonomy for ICUAW and its related syndromes is required to help move both the clinical and research fields forward. Future studies are needed to elucidate the mechanisms by which immobility and other aspects of critical illness lead to neuromuscular dysfunction and injury. In addition, longitudinal studies examining the natural history of ICUAW in ICU survivors and the chronic critically ill are needed, as well as a deeper understanding of the associations between the ICUAW, physical function, and quality of life in these patients.

Currently, there are limited interventions to prevent or treat ICUAW, with tight glycemic control having the greatest supporting evidence. Emerging data demonstrate the safety, feasibility, and potential benefit of early mobility in 


\section{Critical Illness Neuromyopathy and the Role of Physical Therapy and Rehabilitation}

critically ill patients with the need for multicenter randomized trials to evaluate potential short- and long-term benefits of early mobility, including the potential to prevent the need for PMV and/or the development of chronic critical illness, and other novel treatments on patients' muscle strength, physical function, quality of life, and resource utilization. Barriers, both real and perceived, to the implementation of early mobility programs in medical ICUs need to be elucidated to aid in uptake and provide targets for quality improvement efforts. Finally, the barriers, feasibility, and efficacy of early mobility in other ICUs (eg, surgical, neurological, pediatric) and in the chronic critically ill have not been formally evaluated and require exploration in future clinical trials.

\section{ACKNOWLEDGMENTS}

I would like to thank Dale M Needham MD PhD, Division of Pulmonary and Critical Care Medicine, Johns Hopkins University, Baltimore, Maryland, for reviewing an earlier draft of this paper.

\section{REFERENCES}

1. Zambon M, Vincent J-L. Mortality rates for patients with acute lung injury/ARDS have decreased over time. Chest 2008;133(5):1120-1127.

2. Martin GS, Mannino DM, Eaton S, Moss M. The epidemiology of sepsis in the United States from 1979 through 2000. N Engl J Med 2003;348(16): 1546-1554.

3. Stevens RD, Dowdy DW, Michaels RK, Mendez-Tellez PA, Pronovost PJ, Needham DM. Neuromuscular dysfunction acquired in critical illness: a systematic review. Intensive Care Med 2007;33(11): 1876-1891.

4. De Jonghe B, Sharshar T, Lefaucheur JP, Authier FJ, DurandZaleski I, Boussarsar M, et al. Paresis acquired in the intensive care unit: a prospective multicenter study. JAMA 2002;288(22):2859-2867.

5. Fletcher SN, Kennedy DD, Ghosh IR, Misra VP, Kiff K, Coakley JH, Hinds CJ. Persistent neuromuscular and neurophysiologic abnormalities in long-term survivors of prolonged critical illness. Crit Care Med 2003;31(4):1012-1016.

6. Herridge MS, Cheung AM, Tansey CM, Matte-Martyn A, Diaz Granados N, Al-Saidi F, et al. One-year outcomes in survivors of the acute respiratory distress syndrome. N Engl J Med 2003;348(8): 683-693.

7. Herridge MS, Tansey CM, Matté A, Tomlinson G, Diaz-Granados $\mathrm{N}$, Cooper A, et al. Functional disability 5 years after acute respiratory distress syndrome. N Engl J Med 2011;364(14):1293-1304.

8. Koo KK, Choong K, Fan E. Prioritizing rehabilitation strategies in the care of the critically ill. Crit Care Rounds 2011;8(4):1-7.

9. Needham DM. Mobilizing patients in the intensive care unit: improving neuromuscular weakness and physical function. JAMA 2008; 300(14):1685-1690.

10. Truong AD, Fan E, Brower RG, Needham DM. Bench-to-bedside review: mobilizing patients in the intensive care unit: from pathophysiology to clinical trials. Crit Care 2009;13(4):216.

11. Kortebein P, Ferrando A, Lombeida J, Wolfe R, Evans WJ. Effect of 10 days of bed rest on skeletal muscle in healthy older adults. JAMA 2007;297(16):1772-1774

12. Ferrando AA, Lane HW, Stuart CA, Davis-Street J, Wolfe RR. Prolonged bed rest decreases skeletal muscle and whole body protein synthesis. Am J Physiol 1996;270(4 Pt 1):E627-E633.

13. Stein TP, Wade CE. Metabolic consequences of muscle disuse atrophy. J Nutr 2005;135(7):1824S-1828S.
14. Kasper CE, Talbot LA, Gaines JM. Skeletal muscle damage and recovery. AACN Clin Issues 2002;13(2):237-247.

15. Berg HE, Larsson L, Tesch PA. Lower limb skeletal muscle function after 6 wk of bed rest. J Appl Physiol 1997;82(1):182-188.

16. Paddon-Jones D, Sheffield-Moore M, Cree MG, Hewlings SJ, Aarsland A, Wolfe RR, Ferrando AA. Atrophy and impaired muscle protein synthesis during prolonged inactivity and stress. J Clin Endocrinol Metab 2006;91(12):4836-4841.

17. Puthucheary Z, Montgomery H, Moxham J, Harridge S, Hart N. Structure to function: muscle failure in critically ill patients. J Physiol (Lond) 2010;588(Pt 23):4641-4648.

18. Delmonico MJ, Harris TB, Visser M, Park SW, Conroy MB, Velasquez-Mieyer P, et al. Longitudinal study of muscle strength, quality, and adipose tissue infiltration. Am J Clin Nutr 2009;90(6): 1579-1585.

19. Hamburg NM, McMackin CJ, Huang AL, Shenouda SM, Widlansky ME, Schulz E, et al. Physical inactivity rapidly induces insulin resistance and microvascular dysfunction in healthy volunteers. Arterioscler Thromb Vasc Biol 2007;27(12):2650-2656.

20. Winkelman C. Inactivity and inflammation in the critically ill patient. Crit Care Clin 2007;23(1):21-34.

21. Bolton CF, Gilbert JJ, Hahn AF, Sibbald WJ. Polyneuropathy in critically ill patients. J Neurol Neurosurg Psychiatr 1984;47(11): 1223-1231.

22. Bolton CF. Neuromuscular manifestations of critical illness. Muscle Nerve 2005;32(2):140-163.

23. Hermans G, de Jonghe B, Bruyninckx F, Berghe G. Clinical review: critical illness polyneuropathy and myopathy. Crit Care 2008;12(6): 238

24. Herkert M, Becker C, Hacke W. A humoral neurotoxic factor in sera of patients with critical illness polyneuropathy. Ann Neurol;1996; 539 .

25. Friedrich O, Hund E, Weber C, Hacke W, Fink RHA. Critical illness myopathy serum fractions affect membrane excitability and intracellular calcium release in mammalian skeletal muscle. J Neurol 2004;251(1):53-65.

26. Massa R, Carpenter S, Holland P, Karpati G. Loss and renewal of thick myofilaments in glucocorticoid-treated rat soleus after denervation and reinnervation. Muscle Nerve 1992;15(11):1290-1298.

27. Fink H, Helming M, Unterbuchner C, Lenz A, Neff F, Martyn JA, Biobner M. Systemic inflammatory response syndrome increases immobility-induced neuromuscular weakness. Crit Care Med 2008; 36(3):910-916

28. Shanely RA, Zergeroglu MA, Lennon SL, Sugiura T, Timlamai T, Enns D, et al. Mechanical ventilation-induced diaphragmatic atrophy is associated with oxidative injury and increased proteolytic activity. Am J Respir Crit Care Med 2002;166(10):1369-1374.

29. Levine S, Nguyen T, Taylor N, Friscia ME, Budak MT, Rothenberg $\mathrm{P}$, et al. Rapid disuse atrophy of diaphragm fibers in mechanically ventilated humans. N Engl J Med 2008;358(13):1327-1335.

30. Fan E, Needham DM. Mechanical ventilation and disuse atrophy of the diaphragm (letter). N Engl J Med 2008;359(1):90-1, author reply 91-2.

31. Hermans G, Wilmer A, Meersseman W, Milants I, Wouters PJ, Bobbaers H, Bruynickx F, et al. Impact of intensive insulin therapy on neuromuscular complications and ventilator dependency in the medical intensive care unit. Am J Respir Crit Care Med 2007;175(5): 480-489.

32. Bercker S, Weber-Carstens S, Deja M, Grimm C, Wolf S, Behse F, et al. Critical illness polyneuropathy and myopathy in patients with acute respiratory distress syndrome. Crit Care Med 2005;33(4): 711-715.

33. Hough CL, Steinberg KP, Thompson BT, Rubenfeld GD, Hudson LD. Intensive care unit-acquired neuromyopathy and corticosteroids 


\section{Critical Illness Neuromyopathy and the Role of Physical Therapy and Rehabilitation}

in survivors of persistent ARDS. Intensive Care Med 2009;35(1): 63-68.

34. Nanas S, Kritikos K, Angelopoulos E, Siafaka A, Tsikriki S, Poriazi $\mathrm{M}$, et al. Predisposing factors for critical illness polyneuromyopathy in a multidisciplinary intensive care unit. Acta Neurol Scand 2008; 118(3):175-181

35. Bednarík J, Vondracek P, Dusek L, Moravcova E, Cundrle I. Risk factors for critical illness polyneuromyopathy. J Neurol 2005;252(3): 343-351.

36. de Letter MA, Schmitz PI, Visser LH, Verheul FA, Schellens RL, Op de Coul DA, van der Meché FG. Risk factors for the development of polyneuropathy and myopathy in critically ill patients. Crit Care Med 2001;29(12):2281-2286.

37. Coakley JH, Nagendran K, Yarwood GD, Honavar M, Hinds CJ. Patterns of neurophysiological abnormality in prolonged critical illness. Intensive Care Med 1998;24(8):801-807.

38. Garnacho-Montero J, Madrazo-Osuna J, García-Garmendia JL, Ortiz-Leyba C, Jiménez-Jiménez FJ, Barrero-Almodóvar A, et al. Critical illness polyneuropathy: risk factors and clinical consequences. A cohort study in septic patients. Intensive Care Med 2001;27(8): 1288-1296.

39. van den Berghe G, Schoonheydt K, Becx P, Bruyninckx F, Wouters PJ. Insulin therapy protects the central and peripheral nervous system of intensive care patients. Neurology 2005;64(8):1348-1353.

40. Hermans G, de Jonghe B, Bruyninckx F, van den Berghe G. Interventions for preventing critical illness polyneuropathy and critical illness myopathy. Cochrane Database Syst Rev 2009;(1):CD006832.

41. Stevens RD, Marshall SA, Cornblath DR, et al. A framework for diagnosing and classifying intensive care unit-acquired weakness. Crit Care Med 2009;37(10 Suppl):S299-S308.

42. Fan E, Zanni JM, Dennison CR, Lepre SJ, Needham DM. Critical illness neuromyopathy and muscle weakness in patients in the intensive care unit. AACN Adv Crit Care 2009;20(3):243-253.

43. Schweickert WD, Hall J. ICU-acquired weakness. Chest 2007;131(5): 1541-1549.

44. On behalf of the guarantors of Brain. Aids to the examination of the peripheral nervous system, 3rd edition. London: Bailliere Tindall; 1986.

45. Hough CL, Lieu BK, Caldwell ES. Manual muscle strength testing of critically ill patients: feasibility and interobserver agreement. Crit Care 2011;15(1):R43

46. Kleyweg RP, van der Meché FG, Schmitz PI. Interobserver agreement in the assessment of muscle strength and functional abilities in Guillain-Barré syndrome. Muscle Nerve 1991;14(11):1103-1109.

47. Fan E, Ciesla ND, Truong AD, Bhoopathi V, Zeger SL, Needham DM. Inter-rater reliability of manual muscle strength testing in ICU survivors and simulated patients. Intensive Care Med 2010;36(6): 1038-1043.

48. Guarneri B, Bertolini G, Latronico N. Long-term outcome in patients with critical illness myopathy or neuropathy: the Italian multicentre CRIMYNE study. J Neurol Neurosurg Psychiatr 2008;79(7):838-841.

49. Khan J, Harrison TB, Rich MM, Moss M. Early development of critical illness myopathy and neuropathy in patients with severe sepsis. Neurology 2006;67(8):1421-1425.

50. Goodman BP, Boon AJ. Critical illness neuromyopathy. Phys Med Rehabil Clin N Am 2008;19(1):97-110, vii.

51. Latronico N, Shehu I, Seghelini E. Neuromuscular sequelae of critical illness. Curr Opin Crit Care 2005;11(4):381-390.

52. Koch S, Spuler S, Deja M, Bierbrauer J, Dimroth A, Behse F, et al. Critical illness myopathy is frequent: accompanying neuropathy protracts ICU discharge. J Neurol Neurosurg Psychiatr 2011;82(3): 287-293.

53. Koo KK, Choong K, Cook D, et al. Development of a Canadian survey of mobilization of critically ill patients in intensive care units: current knowledge, perspectives and practices (abstract). Am J Respir Crit Care Med 2011;(Suppl):A18868

54. Leijten FS, de Weerd AW, Poortvliet DC, De Ridder VA, Ulrich C, Harink-De Weerd JE. Critical illness polyneuropathy in multiple organ dysfunction syndrome and weaning from the ventilator. Intensive Care Med 1996;22(9):856-861.

55. Tepper M, Rakic S, Haas JA, Woittiez AJ. Incidence and onset of critical illness polyneuropathy in patients with septic shock. Neth J Med 2000;56(6):211-214.

56. Berek K, Margreiter J, Willeit J, Berek A, Schmutzhard E, Mutz NJ. Polyneuropathies in critically ill patients: a prospective evaluation. Intensive Care Med 1996;22(9):849-855.

57. Wiener RS, Wiener DC, Larson RJ. Benefits and risks of tight glucose control in critically ill adults: a meta-analysis. JAMA 2008; 300(8):933-944.

58. NICE-SUGAR Study Investigators, Finfer S, Chittock DR, Su SY, Blair D, Foster D, Dhingra V, et al. Intensive versus conventional glucose control in critically ill patients. N Engl J Med 2009;360(13): 1283-1297.

59. Make B, Gilmartin M, Brody JS, Snider GL. Rehabilitation of ventilator-dependent subjects with lung diseases. The concept and initial experience. Chest 1984;86(3):358-365.

60. Martin UJ, Hincapie L, Nimchuk M, Gaughan J, Criner GJ. Impact of whole-body rehabilitation in patients receiving chronic mechanical ventilation. Crit Care Med 2005;33(10):2259-2265

61. Nava S. Rehabilitation of patients admitted to a respiratory intensive care unit. Arch Phys Med Rehabil 1998;79(7):849-854.

62. Morris PE, Goad A, Thompson C, Taylor K, Harry B, Passmore L, et al. Early intensive care unit mobility therapy in the treatment of acute respiratory failure. Crit Care Med 2008;36(8):2238-2243.

63. Gosselink R, Bott J, Johnson M, Dean E, Nava S, Norrenberg M, et al. Physiotherapy for adult patients with critical illness: recommendations of the European Respiratory Society and European Society of Intensive Care Medicine Task Force on Physiotherapy for Critically Ill Patients. Intensive Care Med 2008;34(7):1188-1199.

64. Bailey P, Thomsen GE, Spuhler VJ, Blair R, Jewkes J, Bezdjian L, et al. Early activity is feasible and safe in respiratory failure patients. Crit Care Med 2007;35(1):139-145.

65. Needham DM, Korupolu R, Zanni JM, Pradhan P, Colantuoni E, Palmer JB, et al. Early physical medicine and rehabilitation for patients with acute respiratory failure: a quality improvement project. Archives of Phys Med Rehabil 2010;91(4):536-542.

66. Hopkins RO, Spuhler VJ, Thomsen GE. Transforming ICU culture to facilitate early mobility. Crit Care Clin 2007;23(1):81-96.

67. Girard TD, Kress JP, Fuchs BD, eThomason JW, Schweickert WD, Pun BT, $t$ al. Efficacy and safety of a paired sedation and ventilator weaning protocol for mechanically ventilated patients in intensive care (Awakening and Breathing Controlled trial): a randomised controlled trial. Lancet 2008;371(9607):126-134.

68. Schweickert WD, Pohlman MC, Pohlman AS, Nigos C, Pawlik AJ, Esbrook CL, et al. Early physical and occupational therapy in mechanically ventilated, critically ill patients: a randomised controlled trial. Lancet 2009;373(9678):1874-1882.

69. Winkelman C, Peereboom K. Staff-perceived barriers and facilitators. Crit Care Nurse 2010;30(2):S13-S16.

70. Pohlman MC, Schweickert WD, Pohlman AS, Nigos C, Pawlik AJ, Esbrook CL, et al. Feasibility of physical and occupational therapy beginning from initiation of mechanical ventilation. Crit Care Med 2010;38(11):2089-2094.

71. Misak CJ. ICU-acquired weakness: obstacles and interventions for rehabilitation. Am J Respir Crit Care Med 2011;183(7):845-846.

72. Fan E. What is stopping us from early mobility in the intensive care unit? Crit Care Med 2010;38(11):2254-2255. 


\section{Critical Illness Neuromyopathy and the Role of Physical Therapy and Rehabilitation}

73. Vasilevskis EE, Ely EW, Speroff T, Pun BT, Boehm L, Dittus RS. Reducing iatrogenic risks: ICU-acquired delirium and weakness: crossing the quality chasm. Chest 2010;138(5):1224-1233.

74. Needham DM, Truong AD, Fan E. Technology to enhance physical rehabilitation of critically ill patients. Crit Care Med 2009;37(10 Suppl):S436-S541.

75. Gerovasili V, Stefanidis K, Vitzilaios K, et al. Electrical muscle stimulation preserves the muscle mass of critically ill patients: a randomized study. Crit Care 2009;13(5):R161.

76. Gerovasili V, Tripodaki E, Karatzanos E, Pitsolis T, Markaki V, Zervakis D, et al. Short-term systemic effect of electrical muscle stimulation in critically ill patients. Chest 2009;136(5):1249-1256.

77. Burtin C, Clerckx B, Robbeets C, Ferdinande P, Langer D, Troosters $\mathrm{T}$, et al. Early exercise in critically ill patients enhances short-term functional recovery. Crit Care Med 2009;37(9):2499-2505.

78. Garnacho-Montero J, Amaya-Villar R, García-Garmendía JL, Madrazo-Osuna J, Ortiz-Leyba C. Effect of critical illness polyneuropathy on the withdrawal from mechanical ventilation and the length of stay in septic patients. Crit Care Med 2005;33(2):349 354.

79. Ali NA, O'Brien JM, Hoffmann SP, Phillips G, Garland A, Finley JC, Almoosa K, et al. Acquired weakness, handgrip strength, and mortality in critically ill patients. Am J Respir Crit Care Med 2008; 178(3):261-268.

80. Sharshar T, Bastuji-Garin S, Stevens RD, Durand MC, Malissin I, Rodriguez $\mathrm{P}$, et al. Presence and severity of intensive care unitacquired paresis at time of awakening are associated with increased intensive care unit and hospital mortality. Crit Care Med 2009;37(12): 3047-3053.

81. Intiso D, Amoruso L, Zarrelli M, Pazienza L, Bascinai M, Grimaldi $\mathrm{G}$, et al. Long-term functional outcome and health status of patients with critical illness polyneuromyopathy. Acta Neurol Scand 2011; 123(3):211-219.

82. van der Schaaf M, Beelen A, Dongelmans DA, Vroom MB, Nollet F. Poor functional recovery after a critical illness: a longitudinal study. J Rehabil Med 2009;41(13):1041-1048.

\section{Discussion}

Carson: I want to direct a question to the acute care crowd. The photo of the patient walking is impressive, but equally impressive from the resource point of view is the number of personnel surrounding the patient, even with the personnel-saving device. ${ }^{1}$ With the number of patients you have in the long-term acute care setting, you typically have a good ratio of RTs [respiratory therapists] to patients and a good ratio of PTs [physical therapists] to patients, relative to the hospital, but do you have enough to be as aggressive as would be ideal?

1. Needham DM. Mobilizing patients in the intensive care unit: improving neuromuscular weakness and physical function. JAMA 2008;300(14):1685-1690.

Snyder:* We have a pretty aggressive early mobility program in our long-term acute care hospitals. It is labor-intensive, but we feel that the time is well spent. We have an ag-

\footnotetext{
* Lisa Snyder MD MPH, Select Medical, Me-
} chanicsburg, Pennsylvania. gressive program, and I think that's a good point. You can utilize other people to assist that team, but we have adequate personnel to run that program.

Muldoon: $\dagger$ I would echo that with a couple points. We are pretty intense on getting someone on a ventilator out of bed and into the chair. Walking is more strenuous and therefore less common. We have used a lot of CNAs [certified nursing assistants] rather than nurses and RTs for this process. The other advantage we have, compared to the patients that you showed the photo of, is that essentially all of our patients are tracheotomized, so the airway isn't quite as tenuous, and we can often do a walk with an RT, a nurse, and one or two CNAs.

Girard: Every time you see a paper on early mobility in the ICU, there's always a picture of a patient ambulating while on a ventilator, and I think that's fantastic and it should be our goal. But it does take, at least the way

$\dagger$ Sean R Muldoon MD MPH, Kindred Healthcare, Hospital Division, Louisville, Kentucky. we do it now, several personnel, so sometimes we may miss the fact when we read these papers that it may not take ambulating the ventilated patient to get some benefit.

If you look, for example, at Bill Schweickert's randomized controlled trial, ${ }^{1}$ only $6 \%$ of patients in the intervention group were actually able to ambulate more than a few steps while mechanically ventilated. So I find it hard to attribute all of the benefit, and there were numerous benefits that the intervention group experienced, to just ambulation. I think all of the other things they were doing for those patients, including sitting on the edge of the bed and dangling their feet, balance exercises, active transfer from the bed to the chair-all of those things, I would suspect, have a benefit in that therapy program. And most of those components of the program don't require 4 or 5 people to implement; they can be done with the nurse and an RT or one other person.

1. Schweickert WD, Pohlman MC, Pohlman AS, Nigos C, Pawlik AJ, Esbrook CL, et al. Early physical and occupational therapy in mechanically ventilated, critically ill patients: a randomised controlled trial. Lancet 2009;373(9678):1874-1882. 


\section{Critical Illness Neuromyopathy and the Role of Physical Therapy and Rehabilitation}

Fan: I agree. I think the point of the photo of a patient ambulating is that it's more striking than a patient rolling in the bed with an endotracheal tube in place. But that's the key to where technology and physical therapy assistants or CNAs may be very helpful. So if there is a patient or a few patients in the unit who could ambulate, that's where we want to allocate those skilled therapists to get them up and moving with that high level of activity. And if you have a cycle ergometer, neuromuscular stimulation, or nursing staff available for bedside exercises, then you might apply those to patients who have a lower level of activity, to keep those muscles active and functional, and devote your skilled PT to patients who can do things like dangling or transfer from sit to stand from the chair. I don't disagree; the point was not to say that only by ambulating these patients will the benefits be seen.

Girard: I made the comment not because I thought that you were suggesting that, but because I think some people may think, "Wow, I don't have 5 people to create a mobility team, so I can't do any of this." But in reality they can do these things that may very well benefit their patients.

Fan: Family members might also be very helpful; therapists and nurses can sometimes teach them some exercises they can help the patient with at the bedside.

Snyder: Do you feel there's any role for anabolic steroids in the treatment of ICU-acquired weakness patients?

Fan: We just don't know. As Dean said, it's a data-free zone. It's not clear whether those patients would benefit from anabolic steroids. I think there's some literature about anabolic steroids in patients requiring PMV not being useful, ${ }^{1}$ but I'm not up to date on that.
Specifically on ICU-acquired weakness, there are no data.

1. Bulger EM, Jurkovich GJ, Farver CL, Klotz P, Maier RV. Oxandrolone does not improve outcome of ventilator dependent surgical patients. Ann Surg 2004;240(3): 472-480.

Carson: The data on PMV patients were not very hopeful.

Snyder: Do MRC [Medical Research Council] or other similar types of scores have a role in assessment? How valid do you think the results are?

Fan: This is a big point of controversy that I didn't touch on. At a recent conference on ICU-acquired weakness definitions, sponsored by the American Thoracic Society, we wanted to stress the primacy of the physical examination (ie, manual muscle testing), which would be graded with the MRC score (range 0 to 5) looking at 6 bilateral muscle groups, and having a combined sum score (range 0 to 60). Patients who scored $80 \%$ or less (ie, MRC sum score $\leq 48$ ) would be considered to have clinically detectable weakness. That's been done in a number of studies.

The MRC score has been validated and has excellent reliability in several populations, particularly in patients with Guillain-Barré. We looked at it in ICU survivors, and it had excellent inter-rater reliability, with intraclass correlation coefficients in the range of 0.98 to $1.00 .{ }^{1}$ Hough $^{2}$ recently looked at manual muscle testing in ICU patients, and the biggest problems there were coma, delirium, and/or injury. But among patients who were awake and cooperative it was reasonably reliable with trained operators. Given that it's easy to do (we're all trained on how to do it at the bedside), safe, and cost effective, I believe that manual muscle testing with the MRC sum score would be a good way to detect weakness, until we have a better idea of the role of electrophysiological testing, and how any abnormalities manifest clinically.

1. Fan E, Ciesla ND, Truong AD, Bhoopathi $\mathrm{V}$, Zeger SL, Needham DM. Inter-rater reliability of manual muscle strength testing in ICU survivors and simulated patients. Intensive Care Med 2010;36(6):1038-1043.

2. Hough CL, Lieu BK, Caldwell ES. Manual muscle strength testing of critically ill patients: feasibility and interobserver agreement. Crit Care 2011;15(1):R43.

Bertuola: $\neq$ I'm glad that you broached this subject today, and I think that bringing this to the forefront is hugely important. How we approach it in the skilled nursing facility is a little different. We co-treat with the RTs and OTs [occupational therapists] or PTs to accomplish the same things, working with the patient on their ability to get ambulating. With the design of a skilled nursing facility it's easier to ambulate someone: you don't have so much equipment. You have your backup battery and the $\mathrm{O}_{2}$ tank on the cart with the ventilator, so it's a little easier for us to get patients to a chair or ambulating down the hallway without having to bag them. We get great results and we utilize OTs in weaning patients from a ventilator, because we think they're important for those patients in whom you need to do it more than once a day to get a bigger benefit. Working with OT-putting Therabands on the bed and strengthening the upper extremities-really benefits the patient as well.

Fan: Another major research question is that we don't know the proper "dose" of physical activity to maximize benefit. Is it once a day? Three times a day? Every other day? It's a very important question.

Muldoon: Another unintended good consequence of simply being vertical

$\doteqdot$ Lorraine Bertuola RRT, Genesis Healthcare, Kennett Square, Pennsylvania. 
is that atelectasis gets a little bit better, and the depression of being stuck in bed not getting well tends to be lifted. The biggest one, I suspect, is that if the patient is over-sedated, they can't sit up. So sedation gets addressed much quicker.

Fan: For some people that's also a point of controversy. Are the benefits of this really the therapy, or is it just that you stopped sedating the patient? And it's difficult to know. We have longitudinal data from our ICU rehabilitation program at Hopkins, where we changed sedation. Once our sedation protocol was in place, there was a period of natural variation in the amount of physical therapy "dose" being provided, typically due to therapists going on vacation, going out for continuing education, etc. There was a varying number of therapists in the ICU providing treatments, but the sedation protocol was the same. Using data from this kind of "natural experiment," there still seemed to be a benefit on length of stay, which was the main outcome we looked at in our quality improvement project, despite sedation practices being unchanged. [There is] some supportive evidence that part of it is the mobility, but I'm sure a big part of it is also getting these patients off sedation.
White: In the cardiac literature there are data on the benefits of exercise in particular, studies ${ }^{1}$ done on the effects of exercise on various circulatory factors, including endothelial cells. So, thinking about that and how exercise may actually be improving endothelial repair and also reducing inflammatory mediators, we start to connect early mobility with recovery.

1. Van Craenenbroeck EM, Hoymans VY, Beckers PJ, Possemiers NM, Wuyts K, Paelinck BP, et al. Exercise training improves function of circulating angiogenic cells in patients with chronic heart failure. Basic Research Cardiol 2010;105(5):665-676. 